\title{
Smart Helmet on IOT Technology for Safety and Accident Detection
}

\author{
Tejashwini R \\ UG Student \\ Nagarjuna College of \\ Engineering and Technology \\ Bangalore, India - 562110
}

\author{
Sharanya S \\ UG Student \\ Nagarjuna College of \\ Engineering and Technology \\ Bangalore, India - 562110
}

\author{
Swathi S \\ Associate Professor \\ Nagarjuna College of \\ Engineering and Technology \\ Bangalore, India - 562110
}

\begin{abstract}
IOT made the present generation to connect with the different network of devices for exchanging of the data. Nowadays it had made compulsion on wearing the helmet while riding. In our paper we introduce a helmet which is made smart using the latest IOT technologies. The papers' main objective is to build a safety system that is integrated with the smart helmet and intelligent bike which reduce the chances of two-wheeler accident and drunk drive cases. The pressure sensor check whether the person is wearing helmet or not. Alcohol sensors (Gas sensor) which is installed at the bottom of the helmet detect the alcoholic content in riders' breath. If the rider is not wearing the helmet or if there is any alcohol content found in rider's breath, the bike remains off. The bike will start if and only if the rider wears the helmet provided with no alcoholic content present. When the rider crashes, helmet hits the ground, sensors detect the motion of helmet and reports the occurrence of an accident. It sends information of corresponding location and message to the registered number through GPS \& GSM module respectively. And along with it we are implementing cooling system inside the helmet which would help the rider to stay cool during the climatic changes which in turn reduces the irritation that is created from the helmet.
\end{abstract}

Keywords: Pressure Sensor, Gas Sensor, GPS \& GSM module.

\section{INTRODUCTION}

A Smart Helmet is a protective headgear used by the rider which makes riding safer than before. The idea of inventing the helmet is to do good deeds towards the society. Accidents of two wheelers are increasing drastically day by day which leads to the loss of many lives in the country. The intention of our project is to build a safety measure for the rider which is integrated with the smart helmet and intelligent bike to reduce the accidents two-wheeler.The idea of our project concentrate on four major areas. [1] Position of the helmet. The ignition of the bike will remain off until the rider wears the helmet which is monitored by the pressure sensor that is present inside the helmet. [2] The level of alcohol in the riders breath. If the rider is alcoholic, the bike will still remain off Gas sensor ie., MQ3 alcohol sensor helps us to detect the alcohol content. [3] Accident detection. If accident occurs suddenly, there would be no person to help the victim. In such situation its very much necessary to inform to ambulance or family members. So we create a module which sends immediate message to the registered number with the current location stating that he/she met with an accident at so an so place through GSM and GPS technology. [4] Managing the temperature inside the helmet which continuously monitors the body temperature and tries to maintain the constant temperature which allows the rider to stay cool all time rather than getting irritated due to increase in humidity.

The paper comprises with normal test case for checking the various conditions of occurrence which would be solved using new emerging IOT technologies.

\section{LITERATURE SURVEY}

[1]. Mohd Khairul Amri Kamarudin has established, "Smart Helmet with Sensors for Accident Prevention. This paper provides an intelligent system for two wheeler accident prevention and detection for human life safety. The prevention part involves, Smart Helmet, which automatically checks whether the person is wearing the helmet and has nonalcoholic breath while driving.

[2]. Vijay J, Saritha B, Priyadharshini B,Deepeka S and Laxmi R (2011) has established, "Drunken Drive Protection System". International Journal of Scientific \& Engineering Research. This system efficiently checks the wearing of helmet and drunken driving. By implementing this system a 
safe two wheeler journey is possible which would decrease the head injuries during accidents and also reduce the accidents due to drunken driving. An intelligent system has been embedded in the helmet itself.

[3]. Harish Chandra Mohanta, Rajat Kumar Mahapatra and Jyotirmayee Muduli(2014), " Anti-Theft Mechanism System with Accidental Avoidance and Cabin Safety System for Automobiles". An anti-theft system is any device or methid used to prevent or detect the unauthorized appropriation of items considered valuable. Theft is one of the most common and oldest criminal behaviours.

[4]. Sudarsan K and Kumaraguru Diderot P (2014), "Helmet for Road Hazard Warning with Wireless Bike Authentication and Traffic Adaptive Mp3 Playback". Helmet for road hazard warning is designed with wireless bike authentication and traffic adaptive mp3 playback. The main aim of this project is to encourage people to wear helmet and prevent road accidents, which is achieved. Thus road accidents can be prevented to some extent and safety of bike riders is ensured.

[5]. Safety measures for "Two wheelers by Smart Helmet and Four wheelers by Vehicular Communication", The small voltage of ignition of the two wheelers is grounded. In normal condition when the helmet is wearied the pressure is senses pressure and the RF transmitter radiates the FM modulated signal.

[6]. Nitin Agarwal Anshul Kumar Singh, Pushpendra Pratap Singh, Rajesh Sahani, "SMART HELMET", International Research Journal of Engineering and Technology, volume 2, issue 2, May 2015, “ Next generation motor cycle helmet with sound control and 360 degree vision that will transform your ride. The cross helmet $\mathrm{X} 1$ is a revolutionary motor cycle helmet that will transform your ride.

[7]. D Kumar, S Gupta, S.Kumar, s.Srivastava "Accident detection and reporting system using GPS and GSM module", It aims at finding the occurrence of any accident and reporting the location of the accident to the previously coded numbers so that immediate help can be provided by ambulance or the relative concerned.. Jennifer William, Kaustubh Padwal, Nexon Samuel, Akshay Bawkar Smita Rukhande, "Intelligent Helmet", The intelligent helmet band is an idea which makes motor cycle driving safer than before. This is implemented using GSM and GPS technology. Limit switch is placed in the helmet which will detect whether the rider has worn the helmet or not. If not the bike will not start.

\section{EXISTING SYSTEM}

In existing system, if the person met with an accident we may not ensure the fast first aid treatment; the person may die due to late medication. By using this proposed system, it sends an automatic alert message to the authorized person or ambulance in case of an accident or any emergency situations. The alert message body contains the place and time of the consequences to speed up the first aid service to the victim.

The other existing system is to control the speed in which the biker is going in. The helmet is fixed with all the components and sensors that read the speed of the bike and accordingly instruct the rider to reduce or increase the speed based on the obstacles ahead the bike. It also contains wireless communication which enables the rider to listen to music while he is riding and it also helps in finding the best through the Google map facilities.

Likewise there is also a device which is used to detect the position of helmet ie whether the helmet is worn or not. Alcohol sensing is also available. The drawbacks of existing system are listed below.

- Checking whether the person worn helmet or not is done at initial stage only. If incase helmet is removed later their will not effect on it.

- Same follows in case of alcohol detection, alcohol content is tested only during the starting of the bike.

- Maintenance of temperature inside the helmet is not done.

\section{Proposed System}

The helmet checks if the rider is alcoholic even while he is driving. If the rider drunk and then tries to ride the bike the ignition of the bike is avoided and hence not letting the rider to start the bike. In this system we use Node MCU Microcontroller interfaced with alcohol sensor and it is used to monitor user's breath continuously and sends signals to microcontroller. The microcontroller on encountering alcohol signal from the gas sensor and send the data to motor using $\mathrm{RF}$ transmitter and we connect a RF receiver to motor driver which stops to demonstrate as engine locking. The system 
need push button to start engine. If the alcohol is detected the system locks the engine.

We are also implementing the temperature monitoring system that is fixed inside the helmet which allows the rider to stay cool all the time whenever he wears the helmet to avoid the itching sensation while riding the bike. Advantages of proposed system are.

- User friendly.

- $\quad$ Through GSM module we send message along with current location of the victims so that they can be easily found in case of emergency.

- Through GPS we can even find our bike if its stolen.

\section{Proposed Framework}

The flowchart is a type of diagram that represents a workflow or process. A flowchart can also be defined as a diagrammatic representation of an algorithm, a step-by-step approach to solving a task.Here in our project we consider 4 conditions first and foremost checking whether the helmet is worn. Second the determination of the alcohol content in riders breath. Thirdly checking whether the accident occurred or not and finally checking whether the rider has fallen or not. Based on these conditions the further steps are followed.

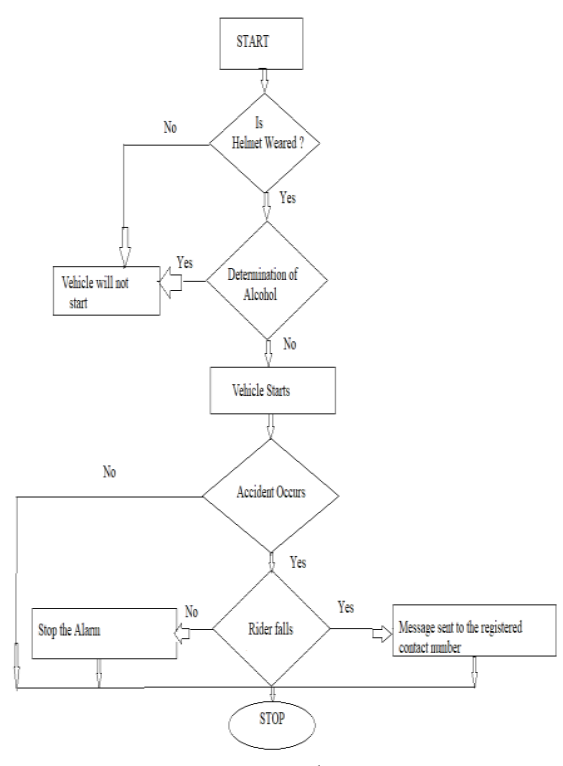

Fig:5.1 Flowchart of the project

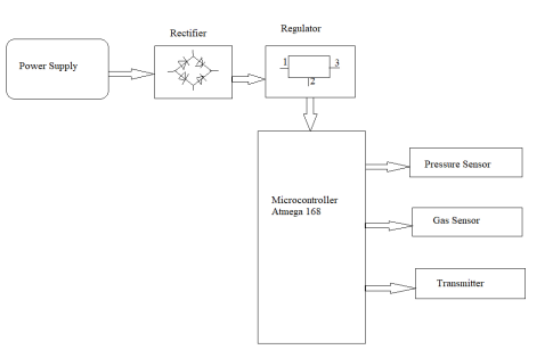

Fig 5.2. Bike unit

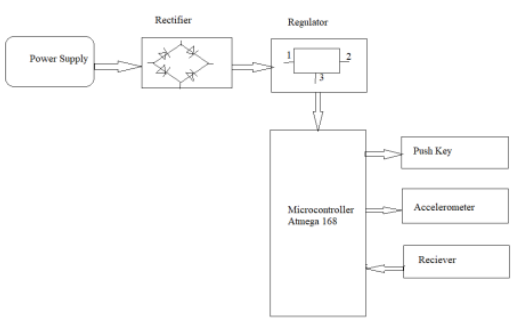

Fig 5.3 Helmet unit

The proposed block diagram shows how the model is implemented. Initially the wearing of helmet by the rider is taken into consideration. Further this input is taken as input for preprocessing unit using algorithm and extracts the features for better accuracy

\section{SPECIFICATIONS}

\section{A. Pressure Sensor}

To measure any gases or liquids we use a device called as pressure sensor. Pressure is generally referred as the force which is required to stop the fluid that's being expanding. The SI unit of pressure sensor is force per unit area. It normally act as a transducer, that generates a signal as a symbol of the pressure imposed. Pressure sensors are used in various fields for controlling and monitoring numerous application. These are normally used in the systems to measure variables like water level, speed, gas/fluid flow and altitude. In our project it is used to detect weather the rider wear the helmet or not. If the rider refuses to wear the helmet bike will not start and intimates the rider to wear the helmet. The pressure sensor is connected with the Arduino in the helmet unit. This sensor works by bending the sensor itself. As the sensors are being flexed or bent, the resistance across the sensor increase. The greater the angle of bending, the greater the resistance. This can be tested with multi-meter. 


\section{B. $M Q-3 /$ Gas Sensor}

Alcohol sensor module - MQ3. This module is made using alcohol gas sensor MQ3. It is a low cost semiconductor sensor which can detect the presence of alcohol gases at concentrations from $0.05 \mathrm{mg} / \mathrm{L}$ to $10 \mathrm{mg} / \mathrm{L}$. When a drunk person breathes near the alcohol sensor it detects the ethanol in his breathe and provides an output based on alcohol concentration, if there is more alcohol concentration more LED's would lit. This sensor provides an analog resistive output based on alcohol concentration. Normally alcoholic limit in our blood is 0.08 in case of alcoholic person it would increase to 0.065 after one hour. It usually take five hours twenty minute to our body to get completely metabolize alcohol and eliminate from the body. And hence till five hours the bike will in OFF state.

\section{Accelerometer ADXL335}

The ADXL335 is a small, thin, low power, complete 3 -axis accelerometer with signal conditioned voltage outputs. The sensor can measure the static acceleration of gravity in tilt sensing applications as well as dynamic acceleration resulting from motion, shock, or vibrations. The acceleration of the bike is measured by this device. The variations and frequency change in the accelerometer gives the bandwidth of the accelerometer.

\section{Node $M C U$}

Node MCU is an open-source firmware and development kit that helps us to prototype or build IoT product. It is low cost and WiFi module chip that can be configured to connect to IoT and similar technology. This module can be used to send the message when the person met with an accident with WiFi connected to it.

\section{Results}

When the pressure sensor becomes flexible, change in resistance occurs and a constant voltage is produced. This voltage is connected to analog pin of arduino. When alcohol is detected, its digital output is connected to the digital input pin of arduino. Here we are using ADXL 335 as a tilt sensor. It has three axes. It is connected to a reset pin. This pin would be set in $\mathrm{x}$-direction and it is according to the variation in tilt to the $\mathrm{y}$ and $\mathrm{z}$ direction that occurrence of accident is detected. GPS is connected to Arduino digital pin and this arduino is connected to Node MCU and it is from this module that the message concerning the occurrence of accident is sent to a predefined number and corresponding location is also specified. An encoder IC is used in the transmitter section. Its function is to encode all the sensor's output and this signal is transmitted by the RF unit except GPS module. The receiver section consists of relay, ignition, power supply and a decoder IC. The transmitted signals are received by using RF receiver and these signals are decoded using HT12D decoder IC. This decoded output is connected to ignition. An npn transistor is given to the ignition to provide voltage to the base and the emitter is grounded. This base voltage makes the transistor on. Relay which is used acts as a switch and it makes the ignition.

\section{CONCLUSION}

The two-wheeler safety system developed with smart helmet and intelligent bike system is reliable and aims to help in the prevention, detection and reporting of accidents hence reducing the probability of the drunk drive cases. It also has several advantages compared to the previous systems. Our proposed system gives the primary importance of preventing the accidents and ensures safety for a greater extent in two wheelers. Nowadays, most accident cases occur due to motor bike. The severities of those accidents are increased because of the absence of helmet or by the usage of alcoholic drinks. By implementing this system, a safe two wheeler journey is possible which would decrease the head injuries throughout accidents caused due to the absence of helmet and additionally reduce the accident rate due to drunken driving. A GSM modem is used in this system that will send a message to the predefined numbers that are programmed using microcontroller in case of any accident.

\section{REFERENCES}

[1]. Smart Helmet with Sensors for Accident Prevention Mohd Khairul Afiq Mohd Rasli, Nina Korlina Madzhi, Juliana Johari Faculty of Electrical Engineering University Tecnology MARA40450 Shah Alam Selangor, MALAYSIAjulia893@ salam.uitm.edu.my)

[2]. Vijay J, Saritha B, Priyadharshini B,Deepeka S and Laxmi R (2011), "Drunken Drive Protection System", International Journal of Scientific \& Engineering Research, Vol. 2, No. 12, ISSN: 2229-5518.

[3]. Harish Chandra Mohanta, Rajat Kumar Mahapatra and Jyotirmayee Muduli(2014)", Anti-Theft Mechanism System 
with Accidental Avoidance and Cabin Safety System for Automobiles", International Refereed Journal of Engineering and Science (IRJES), Vol. 3, No. 4, pp. 56.

[4]. Sudarsan K and Kumaraguru Diderot P (2014), "Helmet for Road Hazard Warning with Wireless Bike Authentication and Traffic Adaptive Mp3 Playback", International Journal of Science andResearch (IJSR), Vol. 3, No. 3, ISSN (Online): 2319-7064.

[5]. Safety measures for "Two wheelers by Smart Helmet and Four wheelers by Vehicular Communication" Manjesh N 1, Prof. Sudarshan raju C H 2 M Tech, ECEDSCE, JNTUA, Hindupur Email: manjesh405@gmail.com HOD \& Asst. Prof. BIT-IT, Hindupur International Journalof Engineering Research and Applications (IJERA) ISSN: 2248-9622 NATIONAL CONFERENCE on Developments, Advances \& Trends in Engineering Sciences (NCDATES09th \& 10th January 2015) .

[6]. Nitin Agarwal, Anshul Kumar Singh, Pushpendra Pratap Singh, Rajesh Sahani, "SMART HELMET", International Research Journal of Engineering and Technology, volume 2, issue 2, May 2015

[7]. D Kumar, S Gupta, S.Kumar, s.Srivastava "Accident detection and reporting system using GPS and GSM module" May 2015. 